\title{
Pensamento Computacional e enriquecimento cognitivo em idosos
}

\author{
Daniel Araújo de Lucena, Karoline da Paz Figueiredo de Macedo, Natália Carvalho \\ Custódio, Isabel Dilmann Nunes
}

\author{
Instituto Metrópole Digital - Universidade Federal do Rio Grande do Norte \\ Natal - RN - Brasil \\ daniel.fafic@gmail.com, bel@imd.ufrn.br, karolinedapazfmegmail.com, \\ nataliaccustodio@gmail.com
}

\section{RESUMO}

Na revista Computação Brasil ${ }^{1} n^{0} 39$, da Sociedade Brasileira de Computação, o presidente da SBC Lisandro Zambenetti afirma que não se imagina hoje uma vida em sociedade sem as facilidades que as tecnologias de informação e comunicação têm a oferecer, onde a Computação se tornou uma realidade, agindo, inclusive, como uma extensão dos sentidos. Diante desse ecossistema tecnológico considera-se que compreender o funcionamento dos recursos digitais e operá-los torna o indivíduo um mero consumidor de tecnologia, necessitando entretanto, ser capaz de formular um problema e expressar sua solução de forma que um computador possa executar. Esse modo de pensar é chamado de Pensamento Computacional (BOUCINHA et al., 2017). O Pensamento Computacional é visto como uma habilidade essencial e muitas iniciativas surgiram para promovê-lo. Encontramos pesquisas no ensino infantil (GOMES, 2018), fundamental e médio (BORDINI et al., 2017), técnico (GERALDES et al., 2017) e superior (KAMPFF et al., 2016). Inclusive, propõe-se que o Pensamento Computacional seja adotado nos cursos de Psicologia como uma abordagem para compreender os fenômenos humanos que se articulam no mundo digital. Mesmo passando 13 anos da publicação "Computational Thinking" de Jeannette Wing, que alavancou discussões sobre as vantagens do Pensamento Computacional, poucos são os trabalhos que o associam aos idosos. Observando, por exemplo, os anais dos workshops do CBIE - Congresso Brasileiro de Informática na Educação , percebe-se que em 2015 foi criado um workshop voltado ao Pensamento Computacional chamado Workshop de Ensino de Pensamento Computacional, Algoritmos e Programação, mas desde então, nada foi publicado para o público 60+. Dos 29 projetos chancelados pela SBC, nenhum conecta o Pensamento Computacional aos idosos. O Pensamento Computacional para o público idoso deve ser encarado além de uma habilidade para intervir num mundo tecnológico, como uma possibilidade de enriquecimento cognitivo, já que para essa parcela da população é comum o declínio cognitivo, que tem como uma das suas consequências, a alteração na capacidade de resolver problemas, fruto dos danos causados às funções executivas. Vale ressaltar que a competência de resolver problemas é listado pelo relatório do Fórum Econômico Mundial ${ }^{2}$ como a principal demandada pelo mercado de trabalho. Se o declínio cognitivo, otimizado sobretudo na senescência, é capaz de comprometer a capacidade de resolução de problemas, isso impacta negativamente na possibilidade do idoso permanecer empregado, indo na

\footnotetext{
${ }^{1}$ https://www.sbc.org.br/images/flippingbook/computacaobrasil/computa_39/pdf/CompBrasil_39_180.p df
}

${ }^{2}$ https://exame.abril.com.br/carreira/10-competencias-que-todo-professional-vai-precisar-ate-2020/ 
contramão do atual cenário brasileiro onde essa faixa da população vem adiando a saída do mercado de trabalho. No entanto, mesmo na velhice o cérebro é capaz de modificar sua organização estrutural e funcional em resposta à estímulos, reduzindo danos a eventuais lesões sofridas. Servindo-se da plasticidade, uma alternativa para estimular a cognição em idosos é o uso do treino cognitivo, por ser uma atividade estruturada para excitar capacidades cognitivas. A presente proposta propõe a aplicação de um treino cognitivo de 6 sessões elaborado por um psicólogo num grupo de controle formado por 15 idosos. Um segundo grupo (grupo de experimento), também constituído de 15 idosos, realizará atividades desplugadas de Pensamento Computacional durante 6 encontros. Em ambos os grupos (controle e experimento) cada sessão deverá ser realizada uma vez por semana. Antes e após as sessões em ambos os grupos, o teste de Avaliação Rápida das Funções Cognitivas deverá ser realizado para investigar possíveis melhorias cognitivas. Os pós-testes de ambos os grupos deverão ser comparados. Se os resultados foram semelhantes, pode-se propor as sessões de atividades de Pensamento Computacional como uma intervenção cognitiva voltada ao estímulo da habilidade de resolução de problemas. Se o pós-teste do grupo experimental obtiver resultado inferior ao grupo de controle, considera-se rever as etapas de elaboração das sessões, o perfil do público-alvo e a quantidade de sessões. Umas das dificuldades é o fato das atividades existentes que buscam estimular o Pensamento Computacional terem sido criadas para faixas etárias mais jovens da sociedade, necessitando a criação e/ou adaptação de materiais para os idosos. Acredita-se também que é indispensável o desenvolvimento de abordagens de aprendizagem para a mesma faixa etária, como há para a educação básica ${ }^{3}$ Incluir os idosos durante o processo de desenvolvimento de um produto e/ou serviço específico pode ajudar o público sênior a sentir-se incluído e/ou representado por empresas e marcas, pois os mesmos encontram dificuldades para encontrar produtos e/ou serviços adequados a seu momento de vida ${ }^{4}$. Inserir disciplinas focadas nos idosos, mesmo que sejam opcionais, em diferentes cursos de graduação, é uma alternativa para fomentar pesquisas com a colaboração de diferentes profissionais, pois envelhecer com autonomia é um anseio de grande parte da população.

\section{REFERÊNCIAS}

BORDINI, Adriana et al. Pensamento Computacional nos Ensinos Fundamental e Médio: uma revisão sistemática. Anais do XXVIII Simpósio Brasileiro de Informática na Educação (sbie 2017), p.123-132, 27 out. 2017. Brazilian Computer Society (Sociedade Brasileira de Computação - SBC). http://dx.doi.org/10.5753/cbie.sbie.2017.123.

BOUCINHA, Rafael Marimon et al. Construção do Pensamento Computacional através do desenvolvimento de games. Renote, v. 15, n. 1, p.1-10, 28 jul. 2017. Universidade Federal do Rio Grande do Sul. http://dx.doi.org/10.22456/1679-1916.75146.

CHARÃO, Andrea et al. Computação e Psicologia: Construindo uma Parceria Interdisciplinar para o Ensino de Computação em Escolas. Anais dos Workshops do Vii Congresso Brasileiro de Informática na Educação (cbie 2018), p.579-588, 28 out. 2018. Brazilian Computer Society (Sociedade Brasileira de Computação - SBC). http://dx.doi.org/10.5753/cbie.wcbie.2018.579.

\footnotetext{
${ }^{3} \mathrm{http}: / /$ basenacionalcomum.mec.gov.br/images/BNCC_EI_EF_110518_versaofinal_site.pdf

${ }^{4}$ http://hype60mais.com.br/guia-ux-60-mais/
} 
GERALDES, Wendell Bento et al. O Pensamento Computacional no Ensino Profissional e Tecnológico. Anais dos Workshops do VI Congresso Brasileiro de Informática na Educação (cbie 2017), p.902-911, 27 out. 2017. Brazilian Computer Society (Sociedade Brasileira de Computação - SBC). http://dx.doi.org/10.5753/cbie.wcbie.2017.902.

GOMES, Tancicleide Carina Simões. Desenvolvimento do Pensamento Computacional na Educação Infantil: contribuições de uma pesquisa-ação educacional. 2018. Dissertação (Mestrado) - Curso de Pós-graduação em Ciência da Computação, Universidade Federal de Pernambuco, Recife, 2018.

GONZÁLEZ, Marcos Román. Codigoalfabetización y Pensamiento Computacional en educación primaria y secundaria: validación de un instrumento y evaluación de programas. 2016. 720 f. Tese (Doutorado) - Curso de Programa de Doctorado En Educación, Universidad Nacional de Educación a Distancia, 2016.

KAMPFF, Adriana Justin Cerveira et al. Pensamento Computacional no Ensino Superior: Relato de uma oficina com professores da Universidade do Vale do Rio dos Sinos. Anais dos Workshops do V Congresso Brasileiro de Informática na Educação (cbie 2016), [s.1.], v. 1, n. 1, p.1316-1323, 10 nov. 2016. Sociedade Brasileira de Computação - SBC. http://dx.doi.org/10.5753/cbie.wcbie.2016.1316.

ROSSELLI, Mónica; JURADO, María Beatriz; MATUTE, Esmeralda. Las Funciones Ejecutivas a través de la Vida. Revista Neuropsicología, Neuropsiquiatría y Neurociencias, p.23-49, abr. 2008.

SANTOS, Mariana Teles. Desenvolvimento de um programa de intervenção cognitiva para idosos. 2015. 226 f. Tese (Doutorado) - Curso de Programa de Pós-graduação em Psicologia, Universidade Federal de Minas Gerais, Belo Horizonte, 2015.

WING, J. M. (2006). Computational thinking. Communications of the ACM, v. 49, n. 3, p.33-35. 